\title{
Long non-coding RNA HOTAIR and HOTTIP as potential biomarkers for hepatitis $C$ virus genotype 4-induced hepatocellular carcinoma
}

Fawzy Roshdy ${ }^{1 *}$, Mohamed M. S. Farag ${ }^{2}$, Eman El-Ahwany ${ }^{3}$, Ola Mahmode ${ }^{4}$ Adel A. Mousa ${ }^{5}$, Mohamed El Talkawy ${ }^{6}$ and Faiza Essawy ${ }^{4}$

\begin{abstract}
Background: Long non-coding RNAs (IncRNAs) homeobox (Hox) transcript antisense intergenic RNA (HOTAIR) and HOXA transcript at the distal tip (HOTTIP) have been suggested to be implicated in liver cancer tumorigenesis and progression; however, little is known about the role of the plasma HOTAIR and HOTTIP in liver cancer diagnosis and prognosis. The current study aimed at measuring the plasma levels of long non-coding RNAs (HOTAIR and HOTTIP) expression in chronic liver disease (CLD) due to HCV genotype 4 infection with/without cirrhosis and HCC patients in an attempt to evaluate the potential benefits of these new circulating as non-invasive diagnostic biomarkers and a novel therapeutic strategy for liver cirrhosis and carcinogenesis of Egyptian patients. Hundred subjects were included in this study, divided into two groups; group I (50 patients) were classified into subgroup la (CLD without cirrhosis, $n=25$ ) and subgroup Ib (CLD with cirrhosis, $n=25$ ), group II (CLD patients with HCC, $n=25)$, and control (healthy volunteer, $n=25$ ). The expression of IncRNAs (HOTAIR and HOTTIP) genes was analyzed by real-time PCR.

Results: LncRNAs (HOTAIR and HOTTIP) showed upregulation in all diseased groups, which was in consistent with the progression of the disease toward the HCC stage. In addition, HOTAIR and HOTTIP showed a diagnostic ability to discriminate between cases of cirrhosis and HCC compared with healthy control $(p<0.001)$, while HOTAIR and HOTTIP did not show a discrimination significant differences between cirrhotic cases and non-cirrhotic cases. By using receiver operating characteristic curve (ROC) analysis, it was found that LncRNAs (HOTAIR and HOTTIP) could diagnose liver cancer with $64.0 \%$ sensitivity and $86.0 \%$ specificity and $48.0 \%$ sensitivity and $88.0 \%$ specificity. Furthermore, both genes can be considered as the predictor and prognostic parameters for cirrhosis $(\mathrm{OR}=1.111, p$ $=0.05)$ and $(\mathrm{OR}=1.07, p=0.05)$ respectively, and $\mathrm{HCC}(\mathrm{OR}=1.047, p=0.01)$ and $(\mathrm{OR}=1.05, p=0.003)$. The increased HOTAIR and HOTTIP expression were associated with advanced tumor stages and higher grades.
\end{abstract}

Conclusion: These results strongly prompt us that HOTAIR and HOTTIP genes can be used as non-invasive prognostic biomarkers and new therapeutic targets for HCV genotype 4-induced HCC.

Keywords: Biomarker, HOTAIR, HOTTIP, HCV, Cirrhosis, HCC

\footnotetext{
* Correspondence: Drf.roshdy@gmail.com

${ }^{1}$ Molecular Biology, Central Lab, Theodor Bilharz Research Institute (TBRI),

GIZA city, Ministry of Scientific Research, Cairo, Egypt

Full list of author information is available at the end of the article
} 


\section{Background}

Egypt has a very high prevalence of the hepatitis $\mathrm{C}$ virus (HCV) worldwide, about $22 \%$ of Egyptian blood donors suffer from HCV with 170,000 to 200,000 new cases yearly and 40,000 dying from the disease every year "(http:// egyptianstreets.com/2015/05/04/egypt-has-highest-prevalence-of-hepatitis-c-in-the world-who)". HCV infection is a major cause of CLD, which can progress to liver fibrosis, cirrhosis and even HCC [1]. HCV increases the risk of HCC development by nearly 17-fold compared with healthy individuals [2]. Although the overall prevalence of chronic hepatitis $\mathrm{C}$ is declining, the complications of the disease are increasing because of the aging of the infected population and the progression of liver fibrosis [3].

LncRNAs account for a large portion of the non-coding transcripts. They comprise of in excess of 200 nucleotides and have no or restricted protein-coding potential. Previously, they were believed to be transcriptional noise [4]. But recently, expression analyses of lncRNAs in a wide range of tissues have revealed their importance for different homeostatic and physiological functions, such as gene imprinting, cell differentiation, and organogenesis [5, 6]. A solid affiliation has been found between deregulated IncRNA articulation and the improvement of maladies.

Through the modulation of oncogenic and tumorsuppressing pathways, it was noted that the aberrant expression of lncRNAs contributed to the development and progression of cancer [7-10]. LncRNA has attracted attention as a new participant in carcinogenesis and emerged as a new source of non-invasive cancer biomarkers [3, 11-13]. Most of these lncRNAs are upregulated in HCCs, but less expressed or undetectable in normal individuals [14].

The HOX family qualities are realized interpretation factors with a key job in embryogenesis and carcinogenesis $[15,16]$. Their expression is deregulated in many cancers [17]. In humans, HOX genes are organized into 4 clusters $(\mathrm{A}, \mathrm{B}, \mathrm{C}$, and $\mathrm{D})$, which are situated on various chromosomes [18]. Interestingly, several lncRNAs associated with $\mathrm{HOX}$ genomic regions can partake in the regulation of HOX genes and work together in their functions [19]. HOTAIR IncRNA is transcribed from the antisense strand of the HoxC gene, which is located on chromosome 12q13.13 between the HoxC11 and HoxC12 genes [20] and one of the most significant administrative RNAs in human cells. It was first described by Rinn et al. [21] as a spliced and polyadenylated RNA with six exons and $2.2 \mathrm{~kb}$ nucleotides. HOTTIP gene is located at the homeobox A (HOXA) locus (chromosomal locus 7p15.2) which encodes the $3764 \mathrm{bp}$ transcript. Therefore, the IncRNA is termed 'HOXA transcript at the distal tip' (HOTTIP) [22, 23].

HOTAIR promotes the carcinogenic activity of HCC cells via multiple mechanisms, such as the suppression of RNA-binding motif protein, triggering of epithelial- mesenchymal transition, and interaction with miRNAs [24]. The expression of HOTAIR was found to be stimulated by c-Myc in gallbladder cancer cells [25]. c-Myc also may have a pivotal role in hepatocarcinogenesis $[25,26]$. HOTAIR was also noticed to be regulated by IKB kinase [27]. Suppression of HOTAIR was noticed to promote the inhibition of cell proliferation and invasion [28]. HOTTIP is overexpressed in numerous cancers $[23,29,30]$ and in HCC [31]. The knockdown of HOTTIP in pancreatic cancer was found to lead to cell proliferation arrest and impaired cell invasion via inhibiting epithelial-mesenchymal transition [32].

Previous research has shown that circulating noncoding RNAs (nRNA) could be used as a non-invasive biomarker for the early detection of cancers [33-35], such as lncRNAs, can be detected in body fluids and may have diagnostic and prognostic roles in cancer. Recent studies have investigated the clinical implication of cell-free lncRNAs in cancer patients [36, 37].

\section{Aim of the work}

The aim of the study is to develop a non-invasive diagnostic tool based on measuring the plasma levels of different lncRNAs markers namely HOTAIR and HOTTIP in order to detect HCV genotype 4-induced HCC at the early stages of the disease.

\section{Methods \\ Study design}

We are planning a study of subjects in which we will regress their values of the patient's against control. Prior data indicate that the standard deviation of control is 0.6 and the standard deviation of the regression errors will be 1.9. If the true slope of the line obtained by regressing patients against control is 1.7 , we will need to study 25 subjects for each group to be able to reject the null hypothesis that this slope equals zero with probability (power) 90\%. The Type I error probability associated with this test of this null hypothesis is 0.05 .

\section{Patient's criteria}

Patients enrolled in this study were admitted to the Gastroenterology and Hepatology Department in affiliated hospital of our institution from November 2016 to August 2018. Diagnosis of patients was based on full medical history, thorough clinical examination, abdominal ultrasonography and laboratory assessment including $\mathrm{CBC}$, and liver function tests, serological and $\mathrm{HCV}$ genotyping by HybProbe probes with the light cycler carousel-based system.

This study was approved by our institution Ethics Review Board and informed consent was obtained from all the subjects included in this study according to the roles 
of the Declaration of Helsinki 1975. Approval of local ethical committee (REC number 01/19).

\section{Inclusion criteria}

All included patients were suffering from chronic hepatitis C genotype (4), persisting more than 6 months (HCV RNA positive). They did not receive any specific treatment for $\mathrm{HCV}$ during the last 6 months.

All chronic liver disease (CLD) who developed malignancy on top of previous HCV infection. Diagnosis of cirrhosis was depending upon ultrasonographic criteria (surface irregularity, coarse echo pattern, portal vein diameter, splenic size, presence or absence of ascites), laboratory findings of hypoalbuminemia and hypoprothrombinemia, in addition to APRI score (APRI score calculated regarding AST to Platelet Ratio Index (APRI) $=[$ AST Level $(\mathrm{IU} / \mathrm{L}) / \mathrm{AST}$ (upper limit of normal) (IU/ L)]/platelet count $(109 / \mathrm{L}) \times 100, \quad($ normal $<0.05$, CLD without cirrhosis $0.5-1.5$ and cirrhosis $\leq 1.5$ ) [38] and esophageal or gastric varices diagnosed by endoscopy as a sign of portal hypertension in indicated patients. Diagnosis of $\mathrm{HCC}$ was depending upon the presence of focal hepatic lesions diagnosed by abdominal ultrasound and confirmed by triphasic spiral computed tomography (CT) and/or magnetic resonance imaging according to the American Association for the Study of Liver Diseases (AASLD) 2011 guidelines [39].

\section{Exclusion criteria}

The exclusion criteria included any concomitant cause CLD such as patients with history of schistosomiasis, chronic viral diseases other than HCV, dual HBV and HCV infection, non-alcoholic steatohepatitis (NASH), autoimmune hepatitis, biliary disorders, malignancies other than HCC, regular intake of hepatotoxic drugs, alcohol abuse, diabetes, and $\mathrm{HCV}$-infected patients receiving direct-acting antiviral or immunomodulatory interferon- $\alpha$ therapy.

Based on the inclusion and exclusion criteria, 100 patients were included in this study. Seventy-five patients with chronic hepatitis $\mathrm{C}$ were classified into two major groups: group I, CLD without HCC ( $n=50)$, and group II, CLD with HCC $(n=25)$. Group I was further subdivided into two subgroups: (Ia) (CLD without cirrhosis) $(n=25)$ and (Ib) (CLD with cirrhosis) $(n=25)$. In addition, twenty-five age- and sex-matched healthy adults served as a control group.

\section{Specimen collection and handling}

About $7 \mathrm{ml}$ peripheral venous blood were collected under strict aseptic conditions by clean venipuncture using vacuum blood collection tubes and distributed as $2.5 \mathrm{ml}$ in EDTA tubes for complete blood picture, $2.5 \mathrm{ml}$ in another sterile EDTA tube (stored at $-80^{\circ} \mathrm{C}$ ) for viral RNA extraction for $\mathrm{HCV}$ genotyping, miRNA, and mRNA extraction. In addition, $2 \mathrm{ml}$ in a plane tube were allowed to clot at $37^{\circ} \mathrm{C}$, and then centrifuged at 3000 $\mathrm{rpm}$ for $10 \mathrm{~min}$ and the collected serum was stored at $-80^{\circ} \mathrm{C}$ to be used for performing liver and kidney functions, and other specific serological tests.

\section{Laboratory investigations}

All individuals were subjected to general investigations including; haemogram, using an automated cell counter (Celltac 5, Nihon Kohden, Tokyo, Japan). A battery of liver function tests was performed using standard methods. Alpha-fetoprotein (AFP) was measured using an autoanalyzer (Hitachi 736, Hitachi Japan). Coagulation tests were measured using Stago Compact Max, USA. Serological diagnosis of HCV infection was done using Murex anti-HCV, version IV, Murex Diagnostics limited, Dartford, England. HCVRNA by PCR. Hepatitis B surface antigen and HBV core antibody were examined by enzyme-linked immunosorbent assay (ELISA) system assay. Autoimmune hepatitis was investigated by detecting anti-nuclear antibodies (ANA) using the immunospec ANA screen ELISA test system. A serological examination of schistosomiasis (Schistosoma mansoni $\mathrm{Ab}$ ) was done using antibody detection, an in-house ELISA.

HCV genotyping: Viral RNA Extraction was done using a high pure viral RNA kit (version 18, 2011), cat. no: (11858882001) "(https://www.roche.com)". cDNA synthesis (transcriptor first strand) was done according to the cDNA synthesis kit (transcriptor first strand) (version 6.0, 2010), cat. no: (04379012001) "(https://www.roche.com)". $\mathrm{HCV}$ genotyping detection was done using hot start reaction mix detection for PCR using HybProbe probes with the light cycler carousel-based system (version 15, 2011), cat. no: (03003248001) "(https://www.roche.com)".

Target gene expression: Total RNA extraction was done according to a high pure RNA isolation kit (version 12, 2011), cat. no: (11828665001) "(https://www.roche. com)". Gene expression detections were performed using light cycler EvoScript RNA SYBR green I master (version 2, 2017), easy to use reaction mix for one-step RT-qPCR cat. no: (07800134001) "(https://www.roche.com)". The primer sequences are illustrated in Table 1.

Analysis of results depending on the SYBR green I filter combination (465-510) on light cycler EvoScript RNA SYBR green I master and comparative CT methods were applied to analyze data. Housekeeping gene B-actin was used as an endogenous control to normalize the amount of total mRNA in each sample of HOTAIR and HOTTIP between different samples. Genes expression was calculated relative to the control samples (used as the calibrator sample) using the formula 2_ $\Delta \Delta C \mathrm{CT}$ and were expressed as fold change "(https://bitesizebio.com)".

\section{Statistical analysis}

The data were analyzed using Microsoft Excel 2010 and statistical package for social science (SPSS version 24.0) 
Table 1 Primers of genes included in the study

\begin{tabular}{|c|c|c|c|}
\hline Gene & Sequence & $\operatorname{Tm}$ & Reference \\
\hline \multicolumn{4}{|l|}{ HOTAIR } \\
\hline Forward & 5'-GCA GTA GAA AAA TAG ACA TAG GAGA-3' & $580 \mathrm{c}$ & \multirow[t]{2}{*}{ "(https://www.ncbi.nlm.nih.gov/pmc/articles/PMC4774541/)" } \\
\hline Reverse & 5'-AAT GAT AGG GAC ACA TCG GGG AAC T-3' & $580 \mathrm{c}$ & \\
\hline \multicolumn{4}{|l|}{ HOTTIP } \\
\hline Forward & 5'-GTG GGG CCC AGA CCC GC-3' & $580 \mathrm{c}$ & \multirow[t]{2}{*}{ "(https://www.ncbi.nlm.nih.gov/pmc/articles/PMC4637691/)" } \\
\hline Reverse & 5'-AAT GAT AGG GAC ACA TCG GGG AAC T-3' & $580 \mathrm{c}$ & \\
\hline \multicolumn{4}{|c|}{ B-actin (used as an endogenous control to normalize the amount of total mRNA in each sample) } \\
\hline Forward & 5-GCACCACACCTTCTACAATG-3 & $580 \mathrm{c}$ & \multirow[t]{2}{*}{ "(http://hgsv.washington.edu)" } \\
\hline Reverse & 5-TGCTTGCTGATCCACATCTG-3 & $580 \mathrm{c}$ & \\
\hline
\end{tabular}

for Windows (SPSS IBM., Chicago, IL). Continuous normally distributed variables were represented as mean \pm SD with a 95\% confidence interval, while non-normal variables were summarized as median with 25 and 75 percentile, and using the frequencies and percentage for categorical variables; a $p$ value $<0.05$ was considered statistically significant. To compare the means of normally distributed variables between groups, the Student's $t$ test was performed, and the Mann-Whitney test was used in non-normal variables. $\chi^{2}$ test or Fisher's exact test was used to determine the distribution of categorical variables between groups. The diagnostic performance of HOTAIR and HOTTIP was assessed by ROC curves. The area under the ROC (AUROC) was used as an index to compare the accuracy of tests. The cut-off for the diagnosis of the group of the study was taken from the point of maximum combined sensitivity and specificity. The sensitivity and specificity for relevant cut-offs were also displayed. Spearman's rank correlation coefficient ( $r$ ) was done to show the correlation between nonparametric parameters, while Pearson's correlation for parametric parameters. Effect modification was evaluated by stratification, statistical interaction and was assessed by including main effect variables and their product terms in the logistic regression model.

\section{Results}

Individual demographic and routine laboratory characteristics of the studied groups are shown in Table 2 .

Depending on the fold change low, the fold change results showed that the gene expressions of HOTAIR and HOTTIP constantly upregulated in the studied groups (Table 3 ).

Gene expression of HOTAIR in all studied diseased groups was highly significantly $(p<0.001)$ upregulated compared with the control group. There was no significant upregulation in subgroup Ia when compared with subgroup Ib, while group II showed a significant upregulation when compared with subgroup Ia and subgroup Ib ( $p$ $<0.001$ and $p<0.01$ ) respectively (Fig. 1) (Table 4).
In contrast, HOTTIP expression, a highly significantly ( $p$ value $<0.001)$ upregulated in all diseased groups when compared with the control group. But there was no significant difference in subgroup Ia when compared with subgroup Ib. While it was obvious, the expression of HOTTIP in group II was significantly $(p$ value $<0.01$ ) upregulated compared with the subgroup Ia, subgroup Ib, and the group I (Fig. 2) (Table 4).

The correlation study revealed a significant direct moderate correlation of HOTAIR with HOTTIP $(r=0.652$ and $p$ value $=0.001$ (Fig. 3) and fair correlation between HOTAIR with AFP $(r=0.481$ and $p$ value $=0.001)$ (Fig. 4). While there were inverse fair correlations with albumin $(r=$ -0.304 and $p$ value $=0.007)$ (Table 5).

HOTTIP expression showed a significant direct fair correlation with AFP $(r=0.400$ and $p$ value $=0.001)$ (Fig. 5), while there were inverse fair correlations with albumin $(r=-0.392$ and $p$ value $=0.001)$ (Table 5).

Receiver operating curves (ROC) were established to show the diagnostic performances of the HOTAIR and HOTTIP genes in the studied groups (Table 6).

\section{ROC curve}

In HOTAIR gene, for discrimination of cirrhotic group from without cirrhosis grou, it was found that plasma HOTAIR at the cut-off value of 4.7 , with sensitivity of $48.0 \%$ and specificity of $72.0 \%$ with areas under curve (AUC) of 52.0 ( $p$ value $=0.8,95 \%$ confidence interval C.I $35.6 \%-68.4 \%$ ) and accuracy of $60.0 \%$ (Fig. 6a), for discrimination of HCC group from cirrhotic group, it was found that plasma HOTAIR at the cut-off value of > 7.0 , with sensitivity of $64.0 \%$ and specificity of $76.0 \%$ with areas under curve (AUC) of 69.8 ( $p$ value $=0.007$, 95\% confidence interval C.I 55.5\%-84.1\%) and accuracy of $60.0 \%$ (Fig. 6c), and for discrimination of HCC group from CLD patients, it was found plasma HOTAIR at the cut-off value of $>9.2$, with sensitivity of $64.0 \%$ and specificity of $86.0 \%$ with areas under curve (AUC) of 74.2 ( $p$ value $=0.001,95 \%$ confidence interval C.I 61.9\%-86.5\%) and accuracy of $60.0 \%$ (Fig. 6d) (Table 6). 
Table 2 Socio-demographic characteristics, laboratory investigations, and ultrasound finding among patients of the studied groups

\begin{tabular}{|c|c|c|c|c|c|}
\hline & & \multirow[t]{2}{*}{$\begin{array}{l}\text { Control } \\
n=25\end{array}$} & \multicolumn{2}{|c|}{$\begin{array}{l}\text { Group I } \\
\text { (CLD without HCC) N=50 }\end{array}$} & \multirow{2}{*}{$\begin{array}{l}\text { Group ॥ } \\
\text { (CLD with HCC) } \\
n=25\end{array}$} \\
\hline & & & $\begin{array}{l}\text { Subgroup la } \\
\text { (CLD without cirrhosis) } \\
n=25\end{array}$ & $\begin{array}{l}\text { Subgroup Ib } \\
\text { (CLD with cirrhosis) } \\
n=25\end{array}$ & \\
\hline \multicolumn{2}{|l|}{ Age } & $47.1 \pm 8.5$ & $47.7 \pm 9.9$ & $58.9 \pm 9.3 \mathrm{aa}, \mathrm{bb}$ & $56.3 \pm 7.8 \mathrm{aa}, \mathrm{bb}$ \\
\hline \multicolumn{2}{|c|}{$\begin{array}{l}\text { Sex } \\
\text { Female/male }\end{array}$} & $2(08.0 \%) / 23(92.0 \%)$ & $15(60.0 \%) / 10(40.0 \%)$ aа & $12(48.0 \%) / 13(52.0 \%)$ aа & $6(24.0 \%) / 19(76 \%) b b, c c$ \\
\hline \multirow[t]{3}{*}{ US finding } & Cirrhosis & $0(0.0 \%)$ & $0(0.0 \%)$ & $25(100.0 \%)$ & $7(28.0 \%) \mathrm{cc}$ \\
\hline & Splenomegaly & $0(0.0 \%)$ & $3(12.0 \%)$ & 19(76.0\%)bb & $22(88.0 \%) b b, c$ \\
\hline & Ascites & $0(0.0 \%)$ & $0(0.0 \%)$ & $21(84.0 \%)$ & $25(100.0 \%) c$ \\
\hline \multicolumn{2}{|c|}{ ALT (umol/dl) } & $27.5(15.5-31.8)$ & $40.0(17.0-51.0) a$ & $46.5(24.3-84.8) a$ & 55.5 (34.5-82.5)aa, bb \\
\hline \multicolumn{2}{|c|}{ AST (umol/dl) } & $32.0(24.3-38.0)$ & $38.0(28.0-46.0)$ & 44.5 (32.0-69.5)аa & 80.0 (37.3-111.0)aa, bb, c \\
\hline \multicolumn{2}{|l|}{ AFP (ng/ml) } & $2.3(1.5-3.1)$ & $2.2(1.4-4.5)$ & 8.8 (6.5-16.8)aa, bb & 224.0 (44.3-597.5)aa, bb, cc \\
\hline \multicolumn{2}{|c|}{ Albumin (umol/dl) } & $4.1 \pm 0.5$ & $4.1 \pm 0.5$ & $3.1 \pm 1.1 \mathrm{aa}, \mathrm{bb}$ & $2.6 \pm 0.7 a a, b b, c$ \\
\hline \multicolumn{2}{|c|}{ Total bilirubin (umol/dl) } & $0.9(0.8-1.1)$ & $0.6(0.4-0.9) a а$ & $1.4(0.7-3.6) a, b b$ & 1.9 (1.3-5.0)aa, bb, c \\
\hline \multicolumn{2}{|c|}{ Direct bilirubin (umol/dl) } & $0.3(0.2-0.4)$ & $0.2(0.1-0.3) a$ & $0.6(0.2-1.9) a, b b$ & $1.1(0.4-2.5) a a, b b$ \\
\hline \multicolumn{2}{|l|}{ ALP (IU/L) } & $74.3 \pm 19.0$ & $84.9 \pm 30.2$ & $103.2 \pm 35.6 a a, b$ & $202.4 \pm 88.0 a a, b b, c c$ \\
\hline \multicolumn{2}{|l|}{ PT (s) } & $12.4(11.4-12.8)$ & 15.4 (13.2-18.8)aа & $17.8(15.0-20.4)$ aа & 16.3 (14.5-19.0)aа \\
\hline \multicolumn{2}{|l|}{ PC (\%) } & $89.6(78.2-100.0)$ & $64.0(55.0-80.0)$ aа & 52.5 (44.0-73.8)aа & 71.5 (55.0-75.3)aа \\
\hline \multicolumn{2}{|l|}{ INR (s) } & $1.1(1.0-1.1)$ & 1.5 (1.0-1.6)aа & 1.5 (1.2-1.8)aа & $1.4(1.2-1.5) a a$ \\
\hline \multicolumn{2}{|l|}{$\mathrm{HB}(\mathrm{g} / \mathrm{dl})$} & $12.6 \pm 1.4$ & $12.4 \pm 1.6$ & $10.4 \pm 2.2 \mathrm{aa}, \mathrm{bb}$ & $11.2 \pm 2.4 a, b$ \\
\hline \multicolumn{2}{|c|}{ WBCs (/mm3) } & $6.2 \pm 2.3$ & $7.0 \pm 2.8$ & $7.3 \pm 2.6$ & $7.8 \pm 3.1$ \\
\hline \multicolumn{2}{|c|}{ Platelets (/mm3) } & $241.5 \pm 56.5$ & $228.2 \pm 67.3$ & $112.9 \pm 52.9 \mathrm{aa}, \mathrm{bb}$ & $136.1 \pm 82.2 \mathrm{aa}, \mathrm{bb}$ \\
\hline \multicolumn{2}{|l|}{ APRI score } & $0.34 \pm 0.13$ & $0.61 \pm 0.17$ & $1.69 \pm 0.31$ & $2.1 \pm 1.3$ \\
\hline
\end{tabular}

Age, albumin, alkaline phosphates (ALP), hemoglobin (HB), white blood cells (WBCs) and platelets are represented as mean \pm SD; the data were analyzed by $t$ test. But sex and ultrasound (U/S) findings are represented as frequency and percent; the data were analyzed by $X^{2}$ test. While alanine aminotransferase (ALT), aspartate aminotransferase (AST), alpha-fetoprotein (AFP), total bilirubin, direct bilirubin, prothrombin time (PT), prothrombin concentration (PC) and international normalized ratio (INR) are represented as median and interquartile range (25\%-75\%); the data were analyzed by Mann-Whitney $U$ test $p$ value bearing (b) initial is significantly different comparing with HCV group $p$ value bearing (c) initial is significantly different comparing with cirrhotic group $p$ value bearing (\#) initial is significantly different comparing with CLD group 1 initial $p$ value $<0.05$ is significant, 2 initial $p$ value $<0.01$ is highly significant

In HOTTIP gene, for discrimination of cirrhotic group from without cirrhosis group, it was found plasma HOTTIP at the cut-off value of 13.4 , with sensitivity of $32.0 \%$ and specificity of $100.0 \%$ with areas under curve (AUC) of $53.9(p$ value $=0.640,95 \%$ confidence interval C.I $37.1 \%-70.8 \%$ ) and accuracy of $66.0 \%$ (Fig. 7a), for discrimination of HCC group from cirrhotic group, it was found plasma HOTTIP at the cut-off value of > 34.8 , with sensitivity of $36.0 \%$ and specificity of $92.0 \%$ with areas under curve (AUC) of $65.8(p$ value $=0.033$, 95\% confidence interval C.I 51.3\%-80.4\%) and accuracy of $64.0 \%$ (Fig. 7c), and for discrimination of HCC group

Table 3 Biomarkers fold change in the studied groups

\begin{tabular}{|c|c|c|c|c|c|c|c|}
\hline \multirow[t]{3}{*}{ Biomarkers } & \multirow[t]{3}{*}{$\begin{array}{l}\text { Control } \\
n=25\end{array}$} & \multicolumn{4}{|c|}{$\begin{array}{l}\text { Group I } \\
\text { (CLD without HCC) } \\
n=50\end{array}$} & \multirow{2}{*}{\multicolumn{2}{|c|}{$\begin{array}{l}\text { Group II } \\
\text { CLD with HCC } \\
n=25\end{array}$}} \\
\hline & & \multicolumn{2}{|c|}{$\begin{array}{l}\text { Subgroup la } \\
\text { (CLD without cirrhosis) } \\
n=25\end{array}$} & \multicolumn{2}{|c|}{$\begin{array}{l}\text { Subgroup Ib } \\
\text { (CLD with cirrhosis) } \\
n=25\end{array}$} & & \\
\hline & & Fold-change & Type of Regulation & Fold-change & Type of Regulation & Fold-change & Type of Regulation \\
\hline HOTAIR & 1 & 4.1536 & Up & 10.724 & Up & 20.508 & Up \\
\hline HOTTIP & 1 & 3.9372 & Up & 11.46 & Up & 22.788 & Up \\
\hline
\end{tabular}

The fold change results depend on the fold change low: fold-change $(2 \wedge(-$ Delta Delta $\mathrm{Ct}))$ is the normalized gene expression $(2 \wedge(-$ Delta $\mathrm{Ct}))$ in the test sample divided the normalized gene expression $(2 \wedge(-$ Delta $\mathrm{Ct}))$ in the control sample. (Fold-change values less than 1 indicate a negative or downregulation https://www.biostars.org//)) 


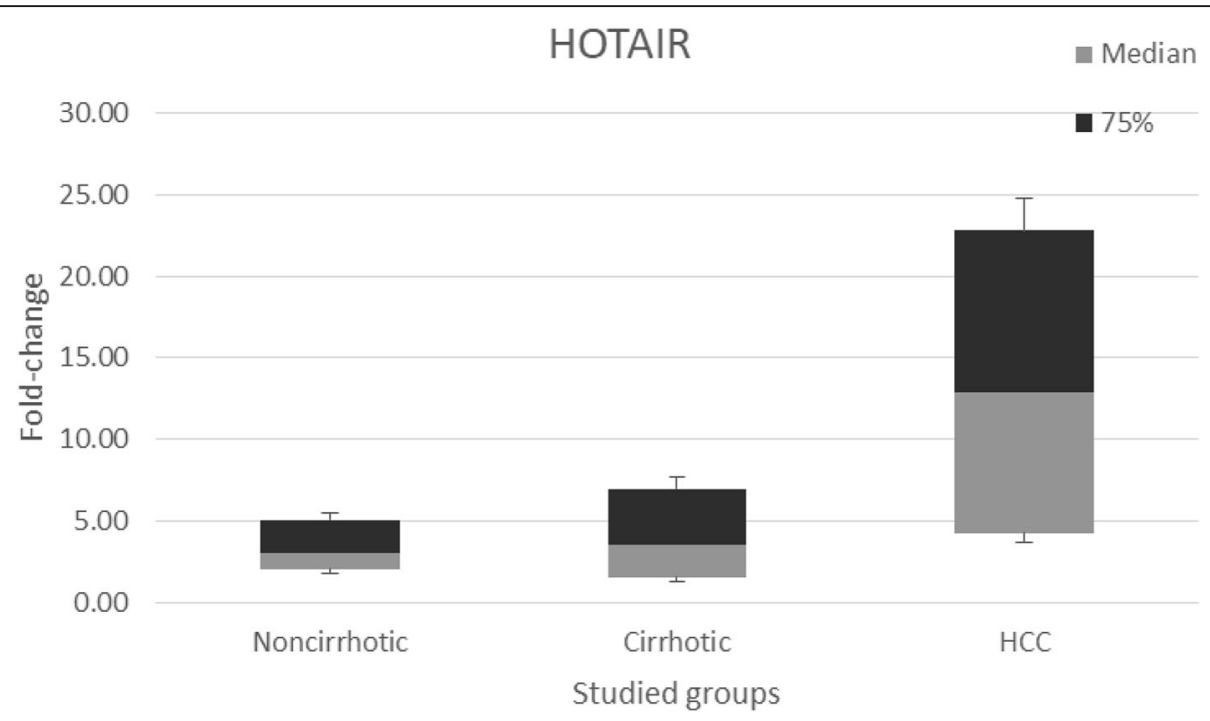

Fig. 1 Box plot of HOTAIR gene expression in studied groups

from CLD patients, it was found plasma HOTTIP at the cut-off value of $>16.6$, with sensitivity of $48.0 \%$ and specificity of $88.0 \%$ with areas under curve (AUC) of $68.3(p$ value $=0.007,95 \%$ confidence interval C.I $55.0 \%-81.7 \%$ ) and accuracy of $74.7 \%$ (Fig. 7d) (Table 6).

Univariate logistic regression analysis performed to characterize the two markers (HOTAIR and HOTTIP) as a predictor and/or prognostic parameter are shown in Table 7.

- Cirrhosis risk according to gene expression

Regarding univariate logistic regression analysis, the HOTAIR and HOTTIP were considered predictor and/ or prognostic parameters for cirrhotic progression. An increase in $1^{\circ}$ of HOTAIR increased the odds of being cirrhosis by a factor of 1.111 with $p$ value $=0.05$, but an increase in $1^{\circ}$ of HOTTIP increased the odds of being cirrhosis by a factor of 1.07 with $p$ value $=0.05$.
- HCC risk according to gene expression

The HOTTIP was considered a predictor and/or prognostic parameter for $\mathrm{HCC}$ progression. An increase in 1 ${ }^{\circ}$ of its expression level increased the odds of being HCC by a factor of 1.029 with $p$ value $=0.05$. But there is no significance for HOTAIR in the characterization of HCC progression $(\mathrm{OR}=1.027, p$ value $=0.1)$.

Concerning CLD as a general group (subgroups Ia and Ib) had an increase in $1^{\circ}$ of HOTAIR which increased the odds of being HCC by a factor of 1.047 with $p$ value $=0.01$. For HOTTIP, an increase in $1^{\circ}$ of HOTTIP which increased the odds of being HCC by a factor of 1.05 with $p$ value $=0.003$.

\section{Discussion}

LncRNAs play a central role in the regulation of differentiation, cell development, and proliferation [40]. Moreover, specific expression of lncRNA in the

Table 4 Biomarkers gene expression in the studied groups

\begin{tabular}{|c|c|c|c|c|}
\hline \multirow[t]{2}{*}{ Biomarkers } & \multirow[t]{2}{*}{$\begin{array}{l}\text { Control } \\
n=25\end{array}$} & \multicolumn{2}{|l|}{$\begin{array}{l}\text { Group I } \\
\text { CLD without HCC }\end{array}$} & \multirow{2}{*}{$\begin{array}{l}\text { Group II } \\
\text { CLD with HCC } \\
n=25\end{array}$} \\
\hline & & $\begin{array}{l}\text { Subgroup la } \\
\text { (CLD without Cirrhosis) } \\
n=25\end{array}$ & $\begin{array}{l}\text { Subgroup Ib } \\
\text { (CLD with Cirrhosis) } \\
n=25\end{array}$ & \\
\hline HOTAIR & 0 & $3.1(2-5.45)^{\mathrm{aa}}$ & $3.6(1.45-9.4)^{\text {aa }}$ & $12.9(3.95-23.35)$ aa, bb, c, \#\# \\
\hline HOTTIP & 0 & $2.4(1.15-5.8)^{\mathrm{aa}}$ & $4.6(0.2-19.95)^{\text {aa }}$ & $14.8(1.55-42.05)^{a a, ~ b, ~ c, ~ \# ~}$ \\
\hline
\end{tabular}

All parameters are represented as median with interquartile range (25\%-75\%) of the fold change of the studied groups, the data were analyzed by Mann-Whitney $U$ test

$p$ value bearing (a) initial is significantly different comparing with control group

$p$ value bearing (b) initial is significantly different comparing with HCV group

$p$ value bearing (c) initial is significantly different comparing with cirrhotic group

$p$ value bearing (\#) initial is significantly different comparing with CLD group

1 initial $p$ value $<0.05$ is significant, ${ }^{2}$ initial $p$ value $<0.01$ is highly significant 


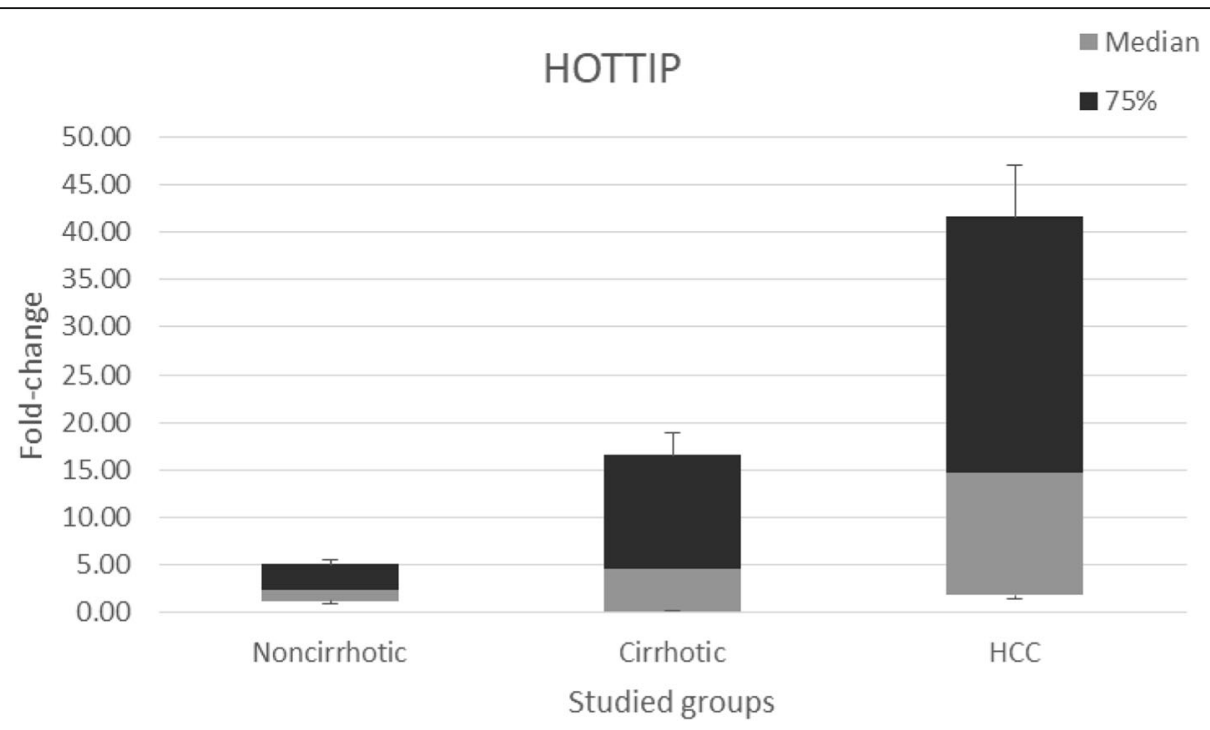

Fig. 2 Box plot of HOTTIP gene expression in studied groups

development of tumors has been revealed and can be used as a promising biomarker to diagnose and monitor tumors, and lncRNAs also could be collected easily from body fluids and tumor tissues [41]. The aim of our study is to develop a non-invasive diagnostic tool based on measuring the plasma levels of different long noncoding RNAs in order to detect HCV-induced HCC at the early stages of the disease.

Our results revealed a significant upregulation of HOTAIR gene in cirrhotic and HCC patients when compared with controls $(p<0.001)$. Similarly, a significant increase was noticed on comparing HCC with chronic HCV without and with cirrhosis patients $(p<0.001, p<$ 0.01 ) respectively. No significant difference was found between chronic $\mathrm{HCV}$ with cirrhosis and chronic $\mathrm{HCV}$ without cirrhosis. Our results are in agreement with Eman et al. [42] and Nande et al. [43] who found a similar increase in HOTAIR expression in patients with gastric cancer and non-small cell cancer patients. Gupta et al. reported that HOTAIR was overexpressed in breast cancer and its high expression in primary breast tumors was a significant predictor of subsequent metastasis and mortality [44]. HOTAIR expression was found to be higher in HCC tissues than in adjacent non-cancerous tissues [13, 45-47].

Regarding HOTTIP gene, a significant upregulation was revealed in cirrhotic and HCC patients when compared with controls $(p<0.001)$. In addition, there is a

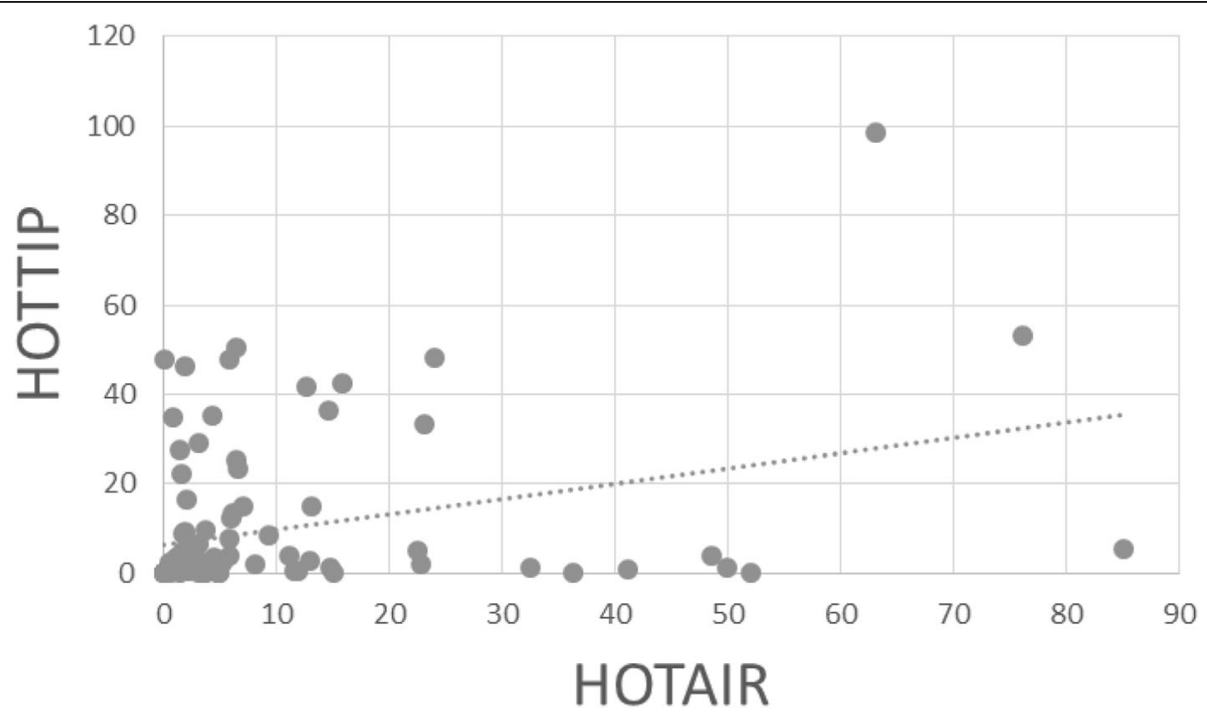

Fig. 3 Correlation between HOTAIR and HOTTIP 


\section{HOTAIR}

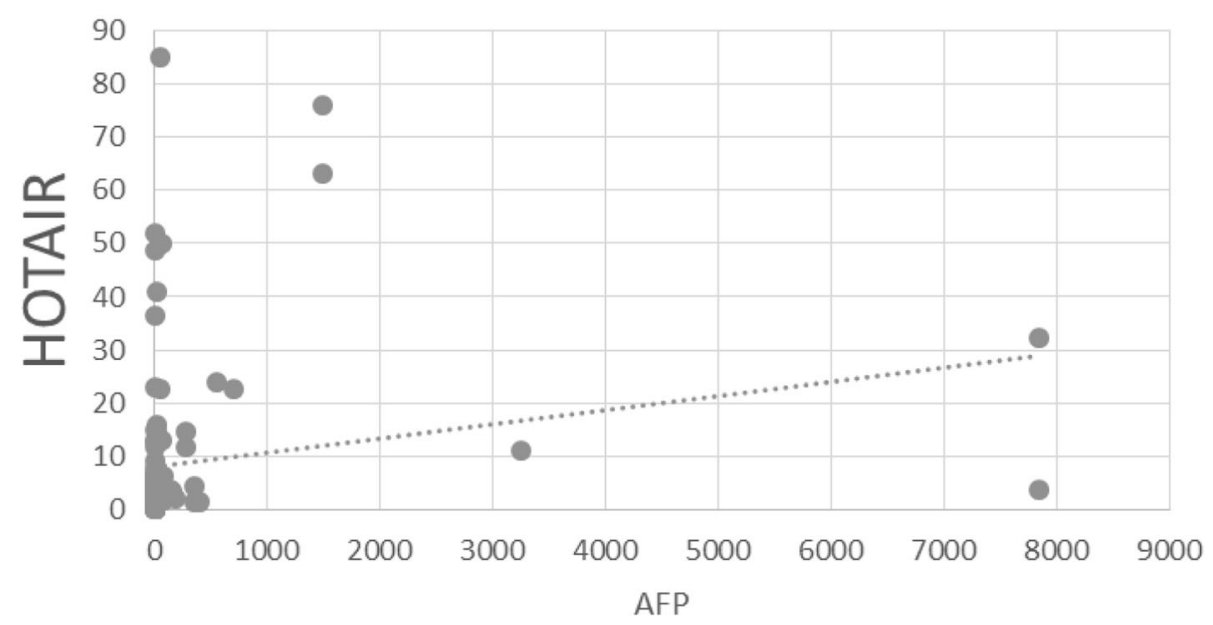

Fig. 4 Correlation between HOTAIR and AFP

Table 5 Correlation study of the studied genes

\begin{tabular}{|c|c|c|c|c|}
\hline & HOTAIR & & HOTTIP & \\
\hline & Correlation coefficient & $\begin{array}{l}\text { Sig. } \\
\text { (2-tailed) }\end{array}$ & Correlation coefficient & $\begin{array}{l}\text { Sig. } \\
\text { (2-tailed) }\end{array}$ \\
\hline HOTAIR & & & $0.652^{* *} \neq$ & 0.001 \\
\hline HOTTIP & $0.652^{* *} \neq$ & 0.001 & & \\
\hline Age & $0.231^{*} \neq$ & 0.044 & 0.202 & 0.078 \\
\hline Sex & -0.211 & 0.065 & -0.221 & 0.054 \\
\hline AFP & $0.481^{* *} \neq$ & 0.001 & $0.400^{* *} \neq$ & 0.001 \\
\hline Albumin & $-0.304^{* *} \neq$ & 0.007 & $-0.392^{* *} \neq$ & 0.001 \\
\hline T. bil & 0.116 & 0.316 & 0.133 & 0.248 \\
\hline D. bil & 0.164 & 0.154 & 0.123 & 0.286 \\
\hline ALT & $0.394^{* *} \neq$ & 0.001 & $0.228^{*} \ddagger$ & 0.046 \\
\hline AST & 0.200 & 0.081 & 0.188 & 0.102 \\
\hline ALP & $0.402^{* *} \neq$ & 0.001 & $0.452^{* *} \neq$ & 0.001 \\
\hline UREA & $0.227^{*} \neq$ & 0.047 & $0.307^{* *} \neq$ & 0.007 \\
\hline CREAT & 0.187 & 0.103 & 0.222 & 0.052 \\
\hline PT & $0.483^{* *} \neq$ & 0.001 & $0.458^{* *} \neq$ & 0.001 \\
\hline PC & $-0.411^{* *} \neq$ & 0.001 & $-0.306^{* *} \neq$ & 0.007 \\
\hline INR & $0.379^{* *} \neq$ & 0.001 & $0.340^{* *} \neq$ & 0.002 \\
\hline$H B$ & -0.172 & 0.135 & -0.200 & 0.08 \\
\hline WBCs & 0.104 & 0.369 & 0.175 & 0.128 \\
\hline Platelets & $-0.418^{* *} \neq$ & 0.001 & $-0.330^{* *} \neq$ & 0.003 \\
\hline
\end{tabular}

All parametric parameters were analyzed by Pearson's correlation test, while all nonparametric parameters were analyzed by Spearman rho (rank correlation) ${ }^{\ddagger}(r)$ Initial is calculated regarding Pearson's correlation test

Results of correlation studies depending on the correlation coefficient values ( $r$ ) as follows: weak $<0.24$; fair $0.25-0.49$; moderate $0.5-0.74$; strong $0.75-1$

Alkaline phosphates (ALP), hemoglobin (HB), white blood cells (WBCs), ultrasound (U/S), alanine aminotrasferase (ALT), aspartate aminotransferase (AST), alpha-

fetoprotein (AFP), total bilirubin (T.Bil), direct bilirubin (D.Bil), prothrombin time (PT), prothrombin concentration (PC) and international normalized ratio (INR)

*Correlation is significant at the 0.05 level (2-tailed)

**Correlation is significant at the 0.01 level (2-tailed) 


\section{HOTTIP}

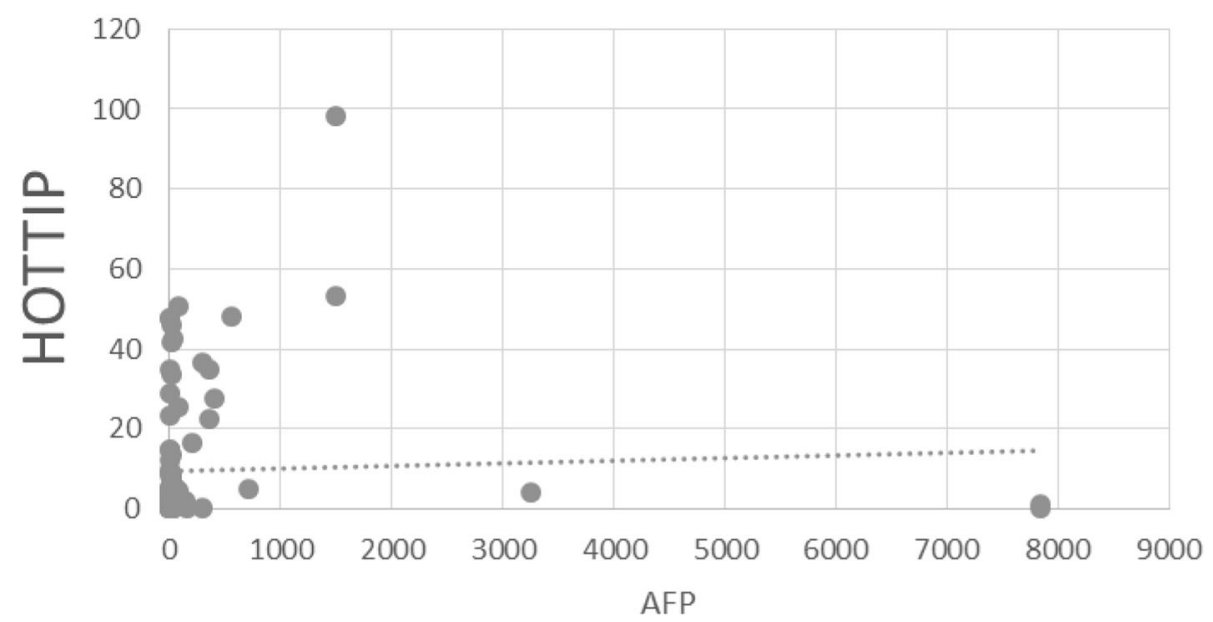

Fig. 5 Correlation between HOTTIP and AFP

significant increase in HCC patients when compared with chronic $\mathrm{HCV}$ without and with cirrhosis patients ( $p$ $<0.01)$. The contribution of HOTTIP as having oncogenic roles has been revealed in tumorigenesis; recent advances have confirmed that HOTTIP is frequently overexpressed in many tumors to play oncogenic roles in cancer development and progression, including HCC [31]. HOTTIP expression was noticed to increase the HCC cell proliferation [48] and was associated with HCC progression and poor clinical outcome $[31,49]$.

The diagnostic performance of HOTAIR and HOTTIP gene expressions as markers in cirrhotic patients at different cut-off points using ROC curve showed that no significant difference between cirrhotic and noncirrhotic patients regarding HOTAIR at the cut-off value of 4.7 , with sensitivity of $48.0 \%$ and specificity of $72.0 \%$ with areas under curve (AUC) of 52.0 ( $p$ value $=0.8$, 95\% confidence interval C.I 35.6\%-68.4\%) and accuracy of $60.0 \%$, also no significant difference between cirrhotic and non-cirrhotic patients regarding HOTTIP at the cut-off value of 13.4 , with sensitivity of $32.0 \%$ and specificity of $100.0 \%$ with areas under curve (AUC) of $53.9(p$ value $=0.640,95 \%$ confidence interval C.I $37.1 \%-70.8 \%)$ and accuracy of $66.0 \%$. The results indicated that HOTAIR and HOTTIP could not be used for discrimination between cirrhotic and non-cirrhotic patients.

In case of HCC, for discrimination of HCC group from cirrhotic group, it was found that a highly significant difference between HCC and cirrhotic patients regarding HOTAIR at the cut-off value of $>7.0$, with sensitivity of $64.0 \%$ and specificity of $76.0 \%$ with areas under curve (AUC) of 69.8 ( $p$ value $=0.007,95 \%$ confidence interval C.I $55.5 \%-84.1 \%)$ and accuracy of $60.0 \%$, also a significant difference between $\mathrm{HCC}$ and cirrhotic patients regarding HOTTIP at the cut-off value of $>34.8$, with sensitivity of $36.0 \%$ and specificity of $92.0 \%$ with areas under curve (AUC) of 65.8 ( $p$ value $=0.033,95 \%$ confidence interval C.I $51.3 \%-80.4 \%$ ) and accuracy of $64.0 \%$. The results indicated that HOTAIR and HOTTIP can be used to discriminate between HCC patients than cirrhotic patients.

Table 6 Diagnostic performances of HOTAIR and HOTTIP to discriminate (cirrhotic and HCC) patients from CLD patients

\begin{tabular}{lllllllllll}
\hline Biomarkers in the studied groups & Cutoff & Sensitivity & Specificity & PPV & NPV & Accuracy & AUC & $95 \%$ Cl & $p$ value \\
\hline HOTAIR & Cirrhotic vs non-cirrhotic & 4.7 & 48.0 & 72.0 & 63.2 & 58.1 & 60.0 & 52.0 & $35.6-68.4$ & 0.8 \\
& HCC vs non-cirrhotic & $>9.2$ & 64.0 & 96.0 & 94.1 & 72.7 & 80.0 & 78.6 & $65.6-91.7$ & $<0.0001^{* *}$ \\
& HCC vs cirrhotic & $>7.0$ & 64.0 & 76.0 & 72.7 & 67.9 & 70.0 & 69.8 & $55.5-84.1$ & $0.007^{* *}$ \\
& HCC vs CLD without HCC & $>9.2$ & 64.0 & 86.0 & 69.6 & 82.7 & 78.7 & 74.2 & $61.9-86.5$ & $0.001^{* *}$ \\
\multirow{2}{*}{ HOTTIP } & Cirrhotic vs non-cirrhotic & 13.4 & 32.0 & 100.0 & 100.0 & 59.5 & 66.0 & 53.9 & $37.1-70.8$ & 0.64 \\
& HCC vs non-cirrhotic & $>13.4$ & 52.0 & 100.0 & 100.0 & 67.6 & 76.0 & 70.8 & $56.2-85.4$ & $0.005^{* *}$ \\
& HCC vs cirrhotic & $>34.8$ & 36.0 & 92.0 & 81.8 & 59.0 & 64.0 & 65.8 & $51.3-80.4$ & $0.03^{*}$ \\
& HCC vs CLD without HCC & $>16.6$ & 48.0 & 88.0 & 66.7 & 77.2 & 74.7 & 68.3 & $55.0-81.7$ & $0.007^{* *}$ \\
\hline
\end{tabular}

PPV Positive predictive value, NPV Negative predictive value and AUC Area under curve, ${ }^{*} p$ value $<0.05$ is significant, ${ }^{* *} p$ value $<0.01$ is highly significant 


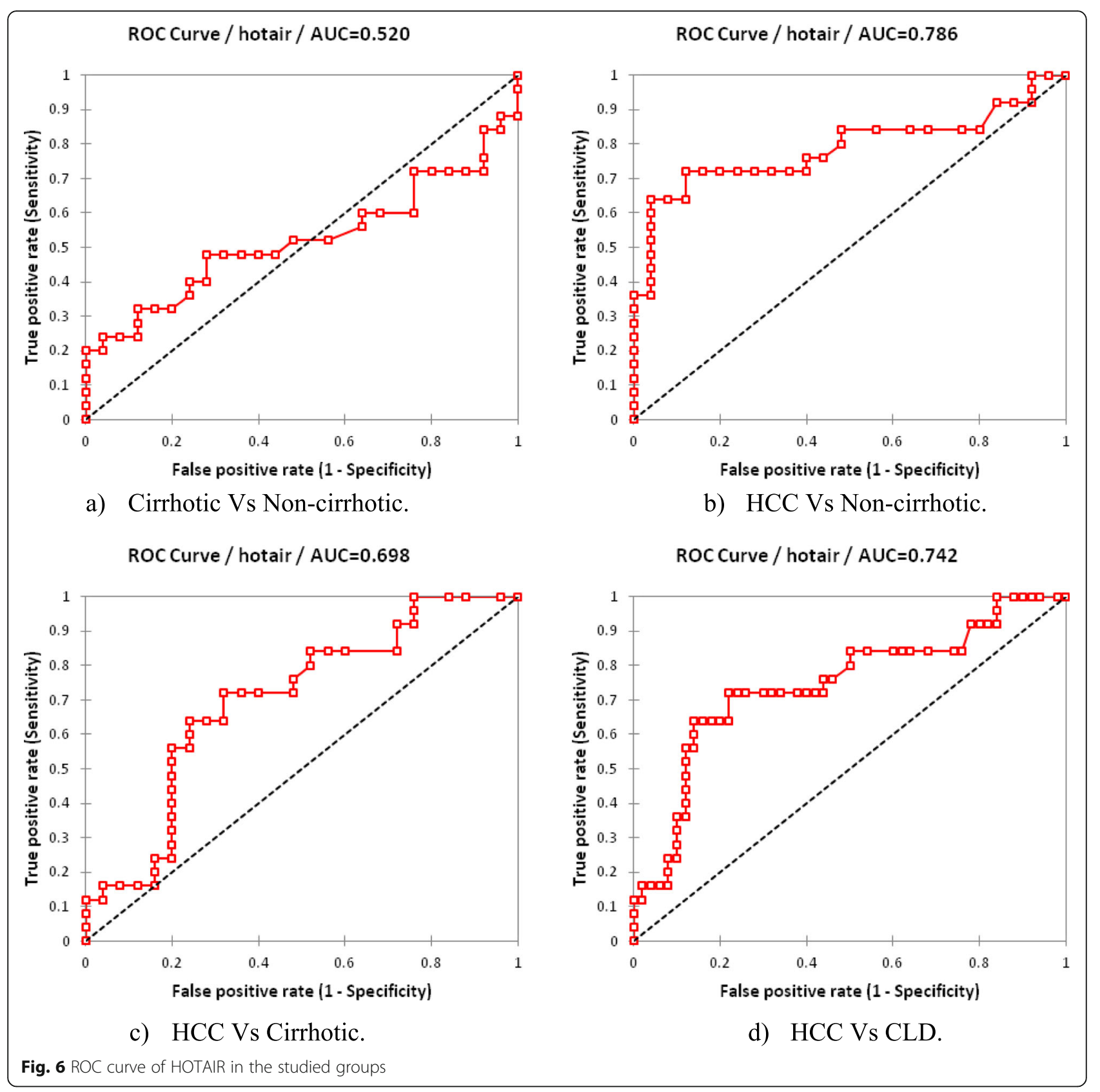

Concerning for discrimination of $\mathrm{HCC}$ patients from CLD (cirrhotic and non-cirrhotic) patients, it was found that a highly significant difference between HCC and CLD patients regarding HOTAIR at the cut-off value of $>9.2$, with sensitivity of $64.0 \%$ and specificity of $86.0 \%$ with areas under curve (AUC) of $74.2(p$ value $=0.001,95 \%$ confidence interval C.I $61.9 \%-86.5 \%$ ) and accuracy of $60.0 \%$, also a highly significant difference between HCC and CLD patients regarding HOTTIP at the cut-off value of $>16.6$, with sensitivity of $48.0 \%$ and specificity of $88.0 \%$ with areas under curve (AUC) of 68.3 ( $p$ value $=0.007,95 \%$ confidence interval C.I $55.0 \%-81.7 \%$ ) and accuracy of $74.7 \%$. These results indicated that HOTAIR and HOTTIP can be used for discrimination between HCC and CLD without HCC.

Interestingly, according to regression analysis, the expression levels of HOTAIR and HOTTIP were considered as significant predictors associated with the changes of the cirrhotic progression and cirrhosis risk assessment ( $p$ value $=0.05$ and $p$ value $=0.05$ ) respectively. Ge et al. suggested that the miR-192/-204- 


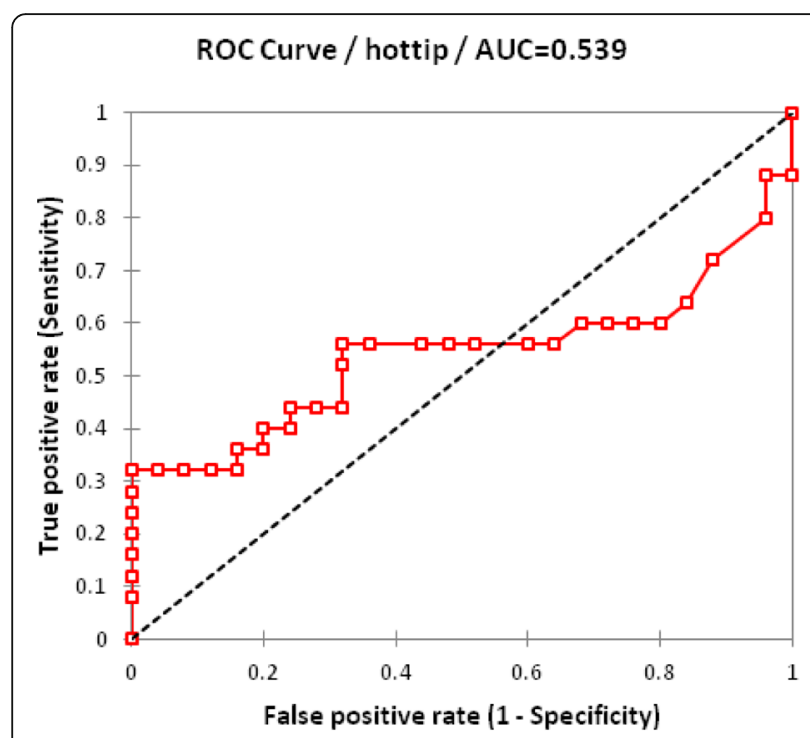

a) Cirrhotic Vs Non-cirrhotic.

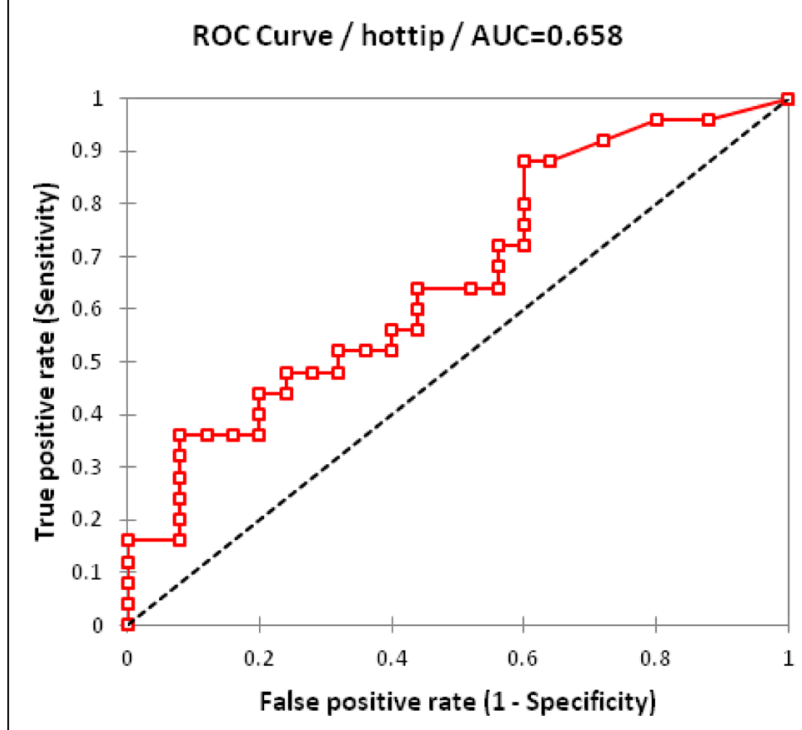

c) HCC Vs Cirrhotic.
ROC Curve / hottip / AUC $=0.708$

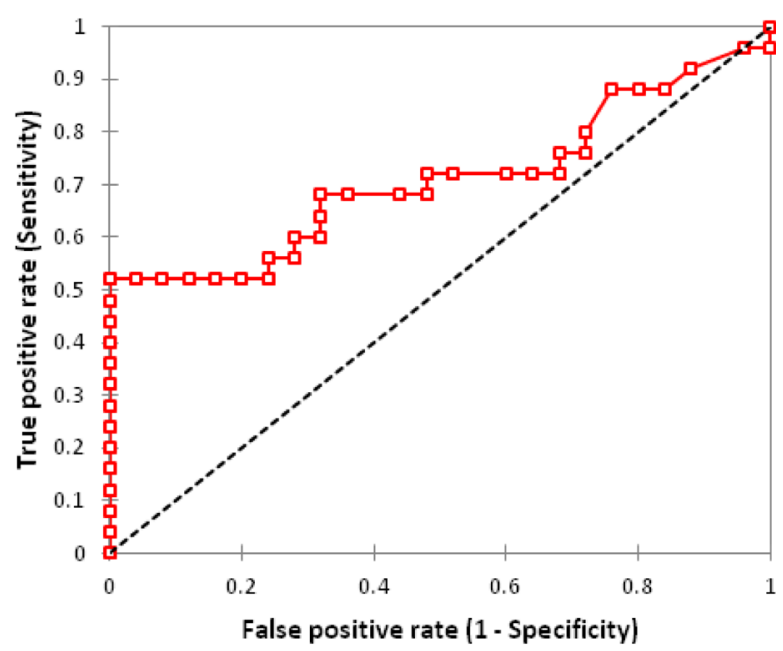

b) HCC Vs Non-cirrhotic.

\section{ROC Curve / hottip / AUC $=0.683$}

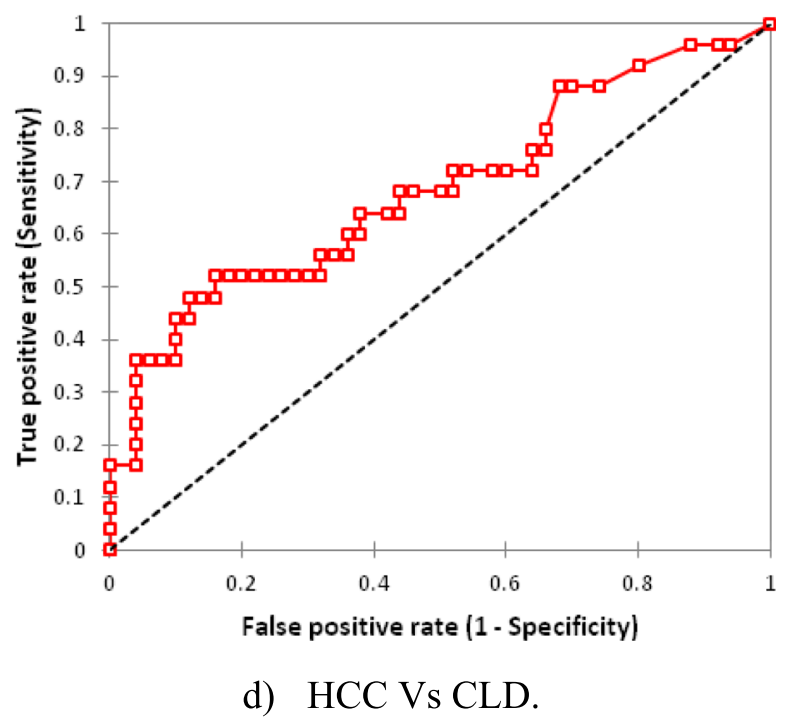

Fig. 7 ROC curve of HOTTIP in the studied groups

HOTTIP axis was a significant molecular pathway during tumorigenesis of $\mathrm{HCC}$ and demonstrated the prognostic and potential therapeutic roles of HOTTIP [50], in contrast, Quagliata et al. reported that the patients with higher IncRNAs HOTTIP/HOXA13 expression had poorer prognosis in liver cancer [32]. Also, overexpression of HOTAIR was found to be strongly associated with unfavorable prognosis for patients with HCC [51]. Evidently, the expression levels of HOTTIP increased the odds of being cirrhosis when selected as significant predictors associated with the chances of diagnosis $\mathrm{HCC}$ versus cirrhosis patients $(p$ value $=0.05)$ and concerning CLD as a general group (non-cirrhotic and cirrhotic) had the expression levels of HOTAIR and HOTTIP were considered as predictor parameters associated with the chances of diagnosis for HCC progression and $\mathrm{HCC}$ risk assessment $(p$ value $=0.01$ and $p$ value $=$ $0.003)$ respectively.

Correlation analysis revealed a significant correlation between HOTAIR and HOTTIP $(r=0.652$ and $p=$ 0.001). A significant direct correlation of HOTAIR and HOTTIP with AFP $(r=0.481$ and $p$ value $=0.001$ and $r$ $=0.400$ and $p$ value $=0.001)$ respectively. A significant inverse correlation of HOTAIR and HOTTIP with 
Table 7 Univariate analysis showing the predictive power of different biomarkers for cirrhosis and HCC diagnosis

\begin{tabular}{lllll}
\hline & Biomarker & OR & $95 \%$ C.I & $p$ value \\
\hline Cirrhotic vs non-cirrhotic & HOTAIR & 1.111 & $0.998-1.236$ & $0.05^{*}$ \\
& HOTTIP & 1.07 & $0.999-1.147$ & $0.05^{*}$ \\
HCC vs non-cirrhotic & HOTAIR & 1.141 & $1.026-1.270$ & $0.01^{*}$ \\
& HOTTIP & 1.103 & $1.030-1.182$ & $0.005^{* *}$ \\
HCC vs cirrhotic & HOTAIR & 1.027 & $0.994-1.062$ & 0.1 \\
& HOTTIP & 1.029 & $0.998-1.062$ & $0.05^{*}$ \\
HCC vs CLD without HCC & HOTAIR & 1.047 & $1.011-1.084$ & $0.01^{*}$ \\
& HOTTIP & 1.05 & $1.017-1.084$ & $0.003^{* *}$ \\
\hline
\end{tabular}

OR Odd ratio, C.I Confidence interval

$p$ value calculated depend on logistic regression analysis, ${ }^{*} p$ value $<0.05$ is significant, ${ }^{* *} p$ value $<0.01$ is highly significant

albumin $(r=-0.304$ and $p$ value $=0.001$ and $r=-0.392$ and $p$ value $=0.001)$ respectively.

\section{Conclusions}

Our results suggested that the gradual overexpression of HOTAIR and HOTTIP gene expressions with the progression of disease prompts us to use it as a noninvasive diagnostic and prognostic biomarkers for $\mathrm{HCV}$ induced $\mathrm{HCC}$ in $\mathrm{HCV}$ genotype 4 patients.

\begin{abstract}
Abbreviations
AASLD: American Association for the Study of Liver Diseases; AFP: Alpha fetoprotein; ALP: Alkaline phosphatase; ALT: Alanine aminotrasferase; ANA: Anti-nuclear antibodies; APRI: AST, platelet ratio index; AST: Aspartate aminotransferase; AUC: Area under the ROC; CLD: Chronic liver disease; $\mathrm{CT}$ : Computed tomography; CT: Threshold; ELISA: Enzyme-linked immunosorbent assay; HCC: Hepatocellular carcinoma; HCV: Hepatitis C virus; HOTAIR: Hox transcript antisense intergenic RNA; HOTTIP: HOXA transcript at the distal tip; HOXC: Homeobox gene C cluster; INR: International normalized ratio; LNCRNAs: Long non-coding RNAs; PC: Prothrombine concentration; PT: Prothrombine time; US: Ultrasound
\end{abstract}

\section{Acknowledgements}

We wish to thank Dr. Rady E. El-Araby (Central Lab, Theodor Bilharz Research Institute (TBRI), Ministry of Scientific Research, Egypt) for statistical analysis.

\section{Authors' contributions \\ FRF made the work design, performance of lab tests, finalized the manuscript and submission. MSF participated in the molecular genetic testing. EGE consultant and drafted the manuscript. OMM patients selection and categorization, integrated the clinical and laboratory data. AAM revised the manuscript, collection of references and consultant. MDE participated in the study design, followed the patients clinically, and supplied the clinical data. FME participated in the study design, supervised the clinical part and finalized the clinical data. All authors approved the manuscript.}

\section{Funding}

This work was funded by Theodor Bilharz Research Institute (Internal project NO: $23 \mathrm{~K}$ ) to submit chemicals but no external fund was received.

\section{Availability of data and materials}

The datasets used and analyzed in the current study are available from the corresponding author upon reasonable request.

\section{Ethics approval and consent to participate}

This study was approved by Theodor Bilharz Research Institute Ethics Review Board and an informed consent was obtained written from all the subjects included in this study according to the roles of the Declaration of Helsinki 1975. Approval of local ethical committee (TBRI-REC number 01/19). Patients enrolled in this study were admitted to Gastroenterology and Hepatology Department, Theodor Bilharz Research Institute, Giza, Egypt from November 2016 to August 2018.

\section{Consent for publication}

Not applicable.

\section{Competing interests}

The authors declare no conflict of interest.

\section{Author details}

Molecular Biology, Central Lab, Theodor Bilharz Research Institute (TBRI), GIZA city, Ministry of Scientific Research, Cairo, Egypt. Virology and Immunology, Botany and Microbiology Department, Faculty of Science, Al-Azhar University, Nasr city, Cairo, Egypt. ${ }^{3}$ Hematology, Clinical Laboratory, Research Department, Theodor Bilharz Research Institute (TBRI), Giza city, Ministry of Scientific Research, Cairo, Egypt. ${ }^{4}$ Hematology, Clinical Laboratory, Research Department, Theodor Bilharz Research Institute (TBRI), Giza city, Ministry of Scientific Research, Cairo, Egypt. ${ }^{5}$ Virology, Botany and Microbiology Department, Faculty of Science, Al-Azhar University, Nasr city, Cairo, Egypt. ${ }^{6}$ Hepatoastroenterology, Hepatoastroenterology Department, Theodor Bilharz Research Institute (TBRI), Giza city, Ministry of Scientific Research, Cairo, Egypt.

Received: 14 October 2019 Accepted: 22 January 2020 Published online: 20 February 2020

\section{References}

1. Zoheiry M, Hasan S, El-Ahwany E, et al (2015): Serum markers of epithelial mesenchymal transition as predictors of HCV-induced liver fibrosis, cirrhosis and hepatocellular carcinoma. Electron Physician 20; 7(8):1626.

2. Bartosch B, Thimme R, Blum HE, Zoulim F (2009): Hepatitis C virus-induced hepatocarcinogenesis. J Hepatol; 51: 810-820[PMID: 19545926 DOl: https:// doi.org/10.1016/j.jhep.2009.05.008].

3. Schanzer D, Paquette D, Lix L (2014) Historical trends and projected hospital admissions for chronic hepatitis $C$ infection in Canada: a birth cohort analysis. CMAJ 2:139

4. Hou J, Meng F, Chan L et al (2016) Circulating plasma MicroRNAs as diagnostic markers for NSCLC. Front Genet 7:193

5. Pauli A, Rinn J, Schier A (2011) Non-coding RNAs as regulators of embryogenesis. Nat Rev Genet 12:136-149

6. Fatica A, Bozzoni I (2014) Long non-coding RNAs: New players in cell differentiation and development. Nat Rev Genet 15:7-21

7. Huarte M, Rinn J (2010) Large non-coding RNAs: Missing links in cancer? Hum Mol Genet 19:R152-R161

8. Xu M, Qi P, Du X (2014) Long non-coding RNAs in colorectal cancer: Implications for pathogenesis and clinical application. Mod Pathol 27:1310-1320

9. Shen X, Qi P, Du X (2015) Long non-coding RNAs in cancer invasion and metastasis. Mod Pathol 28:4-13

10. Chang Y, Zhang K, Hu Z et al (2016) Hypoxia-regulated IncRNAs in cancer. Gene 575:1-8

11. Calin G, Liu C, Ferracin M et al (2007) Ultraconserved regions encoding ncRNAs are altered in human leukemias and carcinomas. Cancer Cell 12:215-229

12. Popov N, Gil J (2010) Epigenetic regulation of the INK4b- ARF-INK4a locus: In sickness and in health. Epigenetics 5:685-690

13. Zhao W, Song M, Zhang J et al (2015) Combined identification of long noncoding RNA CCAT1 and HOTAIR in serum as an effective screening for colorectal carcinoma. Int J Clin Exp Pathol 8:14131-14140

14. Ishibashi M, Kogo R, Shibata K, et al (2013): Clinical significance of the expression of long non-coding RNA HOTAIR in primary hepatocellular carcinoma. Oncol Rep; 29: 946-950 [PMID: 23292722 DOl: https://doi.org/10. 3892/or.2012.2219].

15. Bhatlekar S, Fields JZ, Boman BM (2014) HOX genes and their role in the development of human cancers. J Mol Med 92(8):811-823

16. Shah $N$ and Sukumar S (2010): The Hox genes and their roles in oncogenesis. Nat Rev Cancer.;10(5):361.

17. Plowright L, Harrington K, Pandha H, Morgan R (2009): HOX transcription factors are potential therapeutic targets in non-small-cell lung cancer (targeting HOX genes in lung cancer). Br J Cancer:;100(3):470. 
18. Hoegg S, Meyer A (2005) Hox clusters as models for vertebrate genome evolution. Trends Genet 21(8):421-424

19. Wang $Y$, Dang $Y$, Liu J, Ouyang $X$ (2016) The function of homeobox genes and IncRNAs in cancer. Oncol Lett 12(3):1635-1641

20. Woo CJ, Kingston RE (2007) Hotair lifts noncoding rnas to new levels. Cell 129:1257-1259

21. Rinn J, Kertesz M, Wang J et al (2007) Functional demarcation of active and silent chromatin domains in human HOX loci by noncoding RNAs. Cell 129: 1311-1323

22. Wang KC, Yang YW, Liu B, et al (2011): A long noncoding RNA maintains active chromatin to coordinate homeotic gene expression. Nature. 2011; 472(7341):120.

23. Zhang H, Zhao L, Wang Y-X et al (2015) Long non-coding RNA HOTTIP is correlated with progression and prognosis in tongue squamous cell carcinoma. Tumor Biol 36(11):8805-8809

24. Wu L, Zhang L, Zheng S (2017) Role of the long non-coding rna hotair in hepatocellular carcinoma. Oncol Lett 14:1233-1239

25. Ma MZ, Li CX, Zhang Y et al (2014) Long non-coding RNA HOTAIR, a c-Myc activated driver of malignancy, negatively regulates miRNA-130a in gallbladder cancer. Mol Cancer 13:156

26. Wang L, Zhang X, Jia LT et al (2014) c-Myc-mediated epigenetic silencing of MicroRNA-101 contributes to dysregulation of multiple pathways in hepatocellular carcinoma. Hepatology 59:1850-1863

27. An J, Wu M, Xin X et al (2016) Inflammatory related gene IKKa, IKKß, IKKY cooperates to determine liver cancer stem cells progression by altering telomere via heterochromatin protein 1-HOTAIR axis. Oncotarget 7:50131-50149

28. Gao JZ, Li J, Du JL, Li XL (2016) Long non-coding rna hotair is a marker for hepatocellular carcinoma progression and tumor recurrence. Oncol Lett 11: 1791-1798

29. Ren YK, Xiao Y, Wan XB et al (2015) Association of long non-coding RNA HOTTIP with progression and prognosis in colorectal cancer. Int J Clin Exp Pathol 8(9):11458

30. Ye H, Liu K, Qian K (2016) Overexpression of long noncoding RNA HOTTIP promotes tumor invasion and predicts poor prognosis in gastric cancer. OncoTargets Ther 9:2081

31. Quagliata L, Matter MS, Piscuoglio S et al (2014) Long noncoding RNA HOTTIP/ HOXA13 expression is associated with disease progression and predicts outcome in hepatocellular carcinoma patients. Hepatology. 59(3):911-923

32. Li Z, Zhao X, Zhou $Y$ et al (2015) The long noncoding RNA HOTTIP promotes progression and gemcitabine resistance by regulating HOXA13 in pancreatic cancer. J Transl Med 13:84

33. Resnick K, Alder H, Hagan J et al (2009) The detection of differentially expressed microRNAs from the serum of ovarian cancer patients using a novel real-time PCR platform. Gynecol Oncol 112:55-59

34. Komatsu S, Ichikawa D, Takeshita H et al (2011) Circulating microRNAs in plasma of patients with oesophageal squamous cell carcinoma. Br J Cancer 105:104-111

35. Morimura R, Komatsu S, Ichikawa D et al (2011) Novel diagnostic value of circulating miR-18a in plasma of patients with pancreatic cancer. $\mathrm{Br} J$ Cancer 105:1733-1740

36. Wang W, Sun Y, Huang W et al (2016) Genome-wide long noncoding RNA analysis identified circulating LncRNAs as novel non-invasive diagnostic biomarkers for gynecological disease. Sci Rep 6:23343

37. Wu Y, Wang Y, Weng W, et al (2016): A serum-circulating long non-coding RNA signature can discriminate between patients with clear cell renal cell carcinoma and healthy controls. Oncogenesis 2016; 5: e192.

38. Lin ZH, Xin YN, Dong QJ et al (2011) Performance of the aspartate aminotransferase-to-platelet ratio index for the staging of hepatitis C-related fibrosis: an updated meta-analysis. Hepatology 53:726-736

39. Bruix J, Sherman M (2011) American Association for the Study of Liver Diseases (AASLD) Practice Guidelines. Management of Hepatocellular Carcinoma: An Update. Hepatology 53:1020

40. Wu Y, Liu H, Shi X et al (2015) The long non-coding RNA HNF1AAS1 regulates proliferation and metastasis in lung adenocarcinoma. Oncotarget 6(2015):9160-9172

41. Qi P, Du X (2013) The long non-coding RNAs, a new cancer diagnostic and therapeutic gold mine. Mod Pathol 26:155-165

42. Eman TE, Perihan ES, Azaa MD et al (2018) Plasma long non-coding RNA HOTAIR as a potential biomarker for gastric cancer. The International Journal of Biological Markers 2018. Vol. 33(4):528-533

43. Li N, Wang Y, Liu X et al (2017) Identification of Circulating Long Noncoding RNA HOTAIR as a Novel Biomarker for Diagnosis and Monitoring of Non-Small Cell Lung Cancer. Tecnoligy in cancer research \& treatment 16(6):1060-1066

44. Gupta RA, Shah N, Wang KC et al (2010): Long non-coding RNA HOTAIR reprograms chromatin state to promote cancer metastasis. Nature 464: 1071-1076, 2010.

45. Hajjari M, Salavaty A (2015) HOTAIR: An oncogenic long non-coding RNA in different cancers. Cancer Biol Med 12:1-9

46. Yang F, Zhang L, Huo XS et al (2011) Long noncoding RNA high expression in hepatocellular carcinoma facilitates tumor growth through enhancer of zeste homolog 2 in humans. Hepatology 54:1679-1689

47. Yang Z, Zhou L, Wu LM, et al (2011): Overexpression of long non-coding rna hotair predicts tumor recurrence in hepatocellular carcinoma patients following liver transplantation. Ann Surg Oncol 2011;18:1243-1250.

48. Tsang FH, Au SL, Wei L et al (2015) Long non-coding RNA HOTTIP is frequently up-regulated in hepatocellular carcinoma and is targeted by tumour suppressive miR-125b. Liver Int 35:1597-1606

49. Jin N, Yang LY, Xu ZP (2017) Long non-coding RNA HOTTIP is able to predict poor prognosis in various neoplasms: a meta-analysis. Mol Clin Oncol 7(2):263-266

50. Ge Y, Yan X, Jin $Y$ et al (2015) MiRNA-192 [corrected] and miRNA-204 directly suppress IncRNA HOTTIP and interrupt GLS1-mediated glutaminolysis in hepatocellular carcinoma. PLoS Genet 11:e1005726

51. Geng YJ, Xie SL, Li Q, et al (2011): Large intervening non-coding RNA HOTAIR is associated with hepatocellular carcinoma progression. J Int Med Res; 39: 2119-2128 [PMID: 22289527].

\section{Publisher's Note}

Springer Nature remains neutral with regard to jurisdictional claims in published maps and institutional affiliations.

\section{Submit your manuscript to a SpringerOpen ${ }^{\circ}$ journal and benefit from:}

- Convenient online submission

Rigorous peer review

- Open access: articles freely available online

High visibility within the field

- Retaining the copyright to your article

Submit your next manuscript at $>$ springeropen.com 